\title{
Pengenaan Pajak Penghasilan terhadap Pengusaha dalam Transaksi Perdagangan Online (E-commerce) Studi Pengusaha Online di Yogyakarta
}

\author{
Afrizal Tahar ${ }^{1}$ \\ Fakultas Ekonomi dan Bisnis \\ Universitas Muhammadiyah \\ Yogyakarta, Indonesia
}

\author{
Delvina Dwi Septiani² \\ Fakultas Ekonomi dan Bisnis \\ Universitas Muhammadiyah \\ Yogyakarta, Indonesia
}

\begin{abstract}
Surel : afrizal@umy.ac.id
\section{ABSTRAK}

Penelitian ini dilakukan untuk meneliti mengenai Pengenaan Pajak Penghasilan terhadap Pengusaha dalam Transaksi perdagangan Online. Penelitian ini ditujukan untuk dapat mengetahui persepsi pengusaha online terkait penerapan pajak penghasilan e-commerce. Penelitian ini menggunakan teknik wawancara semi struktur untuk mendapatkan informasi yang diperlukan dalam pengambilan data. Informan pada penelitian dipilih secara purposive sampling dan informan pada penelitian yang berasal dari KPP Pratama Yogyakarta, Konsultan Pajak di Yogyakarta, Pakar Pajak di Yogyakarta, Ahli Teknologi Informasi di Yogyakarta dan Pengusaha Bisnis Online domisili Yogyakarta. Penelitian ini mendapatkan hasil bahwa penghasilan pengusaha bisnis online merupakan objek pajak dan pemungutannya sama dengan pemungutan pajak yang lain. Pengusaha online setuju apabila dikenakan pajak namun dalam batasan transaksi tertentu saja.
\end{abstract}

Kata Kunci: Pajak Penghasilan; Kesadaran Wajib Pajak; ECommerce.

\section{The Imposition of Income Tax on Entrepreneurs in Online Trading Transactions (E-commerce) Study of Online Entrepreneurs in Yogyakarta}

\section{ABSTRACT}

This research was conducted to examine the imposition of income tax on entrepreneurs in online trading transactions. This study aimed to know online entrepreneurs' perceptions regarding the implementation of $e$ commerce income tax. This study employed semi-structured interview techniques to obtain the necessary information in data collection. The informants in the study were selected by purposive sampling, and they came from KPP Pratama Yogyakarta, Tax Consultants in Yogyakarta, Tax Experts in Yogyakarta, Information Technology Experts in Yogyakarta, and Online Business Entrepreneurs domiciled in Yogyakarta. This study's findings revealed that the income of online business entrepreneurs is the tax's object, and the collection is the same as other tax collections. Online entrepreneurs agreed to be taxed but only within specific transaction limits.

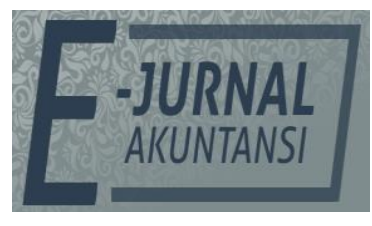

e-ISSN 2302-8556

Vol. 31 No. 6

Denpasar, Juni 2021 Hal. 1390-1400

DOI:

10.24843/EJA.2021.v31.i06.p03

PENGUTIPAN:

Tahar, A., \& Septiani, D.D. (2021). Pengenaan Pajak Penghasilan terhadap

Pengusaha dalam Transaksi Perdagangan Online (Ecommerce) Studi Pengusaha

Online di Yogyakarta. EJurnal Akuntansi, 31(6), 13901400

RIWAYAT ARTIKEL: Artikel Masuk: 10 Desember 2020 Artikel Diterima: 24 Mei 2021

Keywords: Income Tax; Taxpayer's Awareness; E-Commerce.

Artikel dapat diakses : https://ojs.unud.ac.id/index.php/Akuntansi/index 


\section{PENDAHULUAN}

Pesatnya perkembangan teknologi informasi sangat signifikan pada beberapa tahun terakhir. Salah satu perkembangan teknologi yang sangat signifikan ada pada alat komunikasi dan media sosial Berkembangnya teknologi saat ini diimbangi dengan adanya layanan internet yang semakin luas bagi semua orang (Viana et al., 2017). Internet adalah salah satu agen perubahan paling kuat dalam sejarah baru-baru ini (Garín-Muñoz et al., 2019). Pada beberapa tahun lalu layanan internet sulit ditemukan ditempat umum dan relatif mahal. Sekarang layanan internet sudah tersebar secara luas ditempat umum seperti layanan WI-FI. Layanan WI-FI mudah ditemukan ditempat umum dan dapat digunakan oleh siapa saja secara gratis (Laohapensang, 2009). Dengan adanya media sosial, kita dapat memperoleh suatu informasi maupun dapat berkomunikasi dengan mudah tanpa adanya batasan jarak dan waktu (Cahyono, 2016).

Menurut Kompasiana, kemajuan teknologi membawa gebrakan baru (Bukhori, 2019, Januari 31). Perbaharuan fitur serta layanan dilakukan oleh perusahaan perusahaan media sosial. Pada tahun 2004 hingga 2010 muncul perusahaan yang mengembangkan media sosial seperti Facebook, Twitter dan Instagram yang memiliki fitur baru yang semakin menarik, dan kini sudah menjadi konsumsi sehari-hari yang dibutuhkan oleh masyarakat. Dengan berkembangnya zaman saat ini mengakibatkan perubahan yang baru bagi dunia perdagangan. Dalam dunia perdagangan sekarang sudah mulai mengenal perdagangan online atau e-commerce (Makalalag, 2016). Sekarang transaksi ekonomi konvensional sudah mulai ditinggalkan dan beralih ke transaksi digital. Pada awalnya media sosial digunakan untuk sarana berkomunikasi, namun seiring perkembangan zaman media sosial mulai digunakan untuk berbisnis (Rahman \& Panuju, 2017). Pesatnya perkembangan e-commerce telah menjadi momentum baru yang mendorong pertumbungan perdagangan di dunia (Su et al., 2019). Situs web informasi salah satunya situs-situs yang berurusan dengan jual beli informasi yaitu tentu saja e-commerce (Pilkington \& Farron, 2013).

Pertumbuhan pasar e-commerce di Indonesia mengalami kenaikan dari tahun ke tahun, disampaikan oleh Porta Berita ekonomi, Warta Ekonomi.co.I oleh Rahayu (2019). Sejak tahun 2014, dicatat perdagangan online (e-commerce) di Indonesia sudah mencapai US $\$ 1,1$ miliar. Pada 10 tahun terakhir bisnis e-commerce Indonesia mengalami peningkatan yaitu 17 persen dengan total usaha $e$-commerce mencapai 26,2 juta unit yang didapat dari data sensus ekonomi tahun 2019 oleh Badan Pusat Statistik (BPS). Indonesia tercatat telah mengalami peningkatan penggunaan e-commerce yang sangat pesat pada tahun 2018, diperkirakan seiring bertumbuhnya jumlah pengusaha e-commerce maka semakin meningkat pula pertumbuhan e-commerce di Indonesia.

Direktur Consulting Deloitte Southeast Asia, Stanley Kyung Sup Song di Jakarta, Selasa 26 maret 2019 mengatakan bahwa bisnis e-commerce di Indonesia ini akan maju karena hampir 17 persen konsumen lebih memilih produk mahal yang lebih bagus (Ulya, 2019). Menurut Kompas.com yang diterbitkan tanggal 22 maret 2018 15:50 WIB (Tshandra, 2018) karakteristik generasi millenial yang cukup penting dengan teknologi mengakibatkan perusahaan-perusahaan e-commerce memanfaatkannya. E-Commerce sangatlah praktis serta dapat dilakukan setiap saat dan dimana saja tanpa harus bertatap muka dan menyewa tempat untuk 
memamerkan produk tersebut (Viboonthanakul, 2009). E-commerce juga menghindari perjalanan ke toko fisik untuk berbelanja (Dolfen et al., 2019). Hanya mengunggah katalog barang tersebut lalu menuliskan keterangan gambar seperti cara pemesananya, cara pembayarannya, harga, serta rincian barang, warna, ukuran transaksi e-commerce sudah bisa dilakukan (Yapar et al., 2015). Di kalangan anak muda Indonesia E-Commerce menjadi salah satu media perdagangan yang sedang tren. Bahkan anak muda Indonesia juga tidak segan untuk merekomendasikan kepada teman-teman mereka e-commerce atau toko online favorit mereka (Nugroho, 2016).

Untuk menarik seseorang untuk belanja online, pelaku bisnis online harus mempertimbangkan faktor apa yang akan menarik seseorang untuk berbelanja online. Hermanto (2016) menyebutkan bahwa faktor yang berpengaruh adalah biaya yang murah, kualitas jenis barang, kemudahan transaksi, kepercayaan, kualitas informasi sampai dengan beberapa faktor lainnya. Perusahaan berbasis $e-$ commerce seperti olx.com, tokopedia.com, shopee, bukalapak.com, dan lain-lain mulai bermunculan untuk menggeser perusahaan yang masih konvensional. Online shop mudah ditemukan di platform media sosial seperti Facebook, Instagram, maupun aplikasi pengiriman pesan gratis seperti Whatsapp, line, dan lain-lain (Adityowati et al., 2016) dalam (Nugroho, 2016). Maraknya pelaku usaha online shop dan e-commerce mendatangkan pertanyaan yang ditujukan kepada pelaku bisnis online shop. Apakah pelaku bisnis online shop tersebut paham jika kegiatan transaksi online yang sedang mereka lakukan mengandung kewajiban perpajakan? Perlakuan pajak yang diterapkan terhadap pelaku bisnis online shop sama persis dengan perlakuan pajak pelaku bisnis dengan model toko konvensional, yakni $\mathrm{PPh}$. Letak perbedaannya hanya pada fisik toko, yang satu memiliki toko secara fisik, yang satu lagi memiliki domain web ataupun berjualan di platform tertentu. Sehingga pada hakikatnya keduanya adalah sama Menurut Fox (2001), e-commerce juga mengakibatkan kerugian di negara bagian dan lokal karena transaksi $e-$ commerce tidak sebanding dengan penerimaan pajak yang didapatkan. Sehingga niat pemerintah menarik pajak dari semua transaksi $e$-commerce semakin kuat (Adam \& Astin, 2019). Implikasi pajak transaksi e-commerce agak rumit dan memiliki karakteristik yang sangat khusus karena berbeda dengan transaksi perdagangan biasa pada umumnya (Sari, 2018).

Undang-undang perpajakan menyebutkan bahwa siapapun yang memiliki penghasilan maka merupakan objek pajak (Sofyani et al., 2019). Menurut Kompas.com yang diterbitkan tanggal 15 januari 2019, 14:55 WIB (Azanella, 2019) dalam peraturan undang-undang perpajakan tersebut, pemerintah tidak menetapkan besaran atau jenis pajak yang akan dikenakan sebagai pajak penghasilan. Tetapi pemerintah memberikan penjelasan prosedur pemajakan untuk mendorong para pelaku usaha untuk taat pajak. Dengan melihat sistematik kinerja perdagangan online yang minim untuk biaya operasionalnya namun mendapatkan pundi-pundi penghasilan yang bahkan melebihi perdagangan konvensional maka menjadikan pedagang online sudah sepantasnya dikenakan pajak untuk menambah pendapatan negara. Berdasarkan pemaparan, mengenai belum jelasnya pengaturan pemungutan pajak bagi pedagang online (e-commerce) peneliti tertarik untuk melakukan penelitian dengan judul "Pengenaan Pajak Penghasilan Terhadap Pengusaha Dalam Transaksi Perdagangan Online (E- 
Commerce)". Penelitian ini merupakan replikasi dari penelitian yang dilakukan oleh Rosalinawati dan Syaiful (2018)ang membedakan penelitian ini dengan penelitian sebelumnya adalah penelitian ini melakukan studi kasus di Daerah Istimewa Yogyakarta. Berdasarkan masalah yang ada, maka peneliti memberikan batasan pada peneliti yang dilakukan. Batasan ini bertujuan agar pembahasan yang dilakukan dalam penelitian hanyalah masalah yang akan diteliti oleh peneliti. Ruang lingkup dalam penelitian ini terbatas pada lokasi penelitian dan informan yang dipilih hanya yang berdomisili di Daerah Istimewa Yogyakarta. Permasalahan yang dibahas dalam penelitian ini terbatas yaitu, Apakah pengusaha dalam transaksi perdagangan online (e-commerce) dapat dikenakan pajak penghasilan, Bagaimana pemungutan pajak penghasilan terhadap transaksi perdagangan online (e-commerce), Bagaimana persepsi pengusaha online terhadap penerapan pajak atas penghasilan dari perdagangan online.

\section{METODE PENELITIAN}

Penelitian mengambil lokasi diwilayah Yogyakarta. Dalam penelitian ini mengambil subjek yaitu para pelaku bisnis online yang berdomisili di Yogyakarta. Serta subjek lain dalam penelitian ini yaitu Kantor Pelayanan Pajak (KPP) Pratama Yogyakarta, Konsultan Pajak dan Pakar Pajak di Yogyakarta, Ahli Teknologi Informasi di Yogyakarta. Penelitian ini adalah penelitian kualitatif dengan mengunakan jenis data primer. Narasumber disini meliputi pedagang online, Kantor Pelayanan Pajak (KPP) Pratama Yogyakarta, Konsultan Pajak di Yogyakarta, Pakar Pajak di Yogyakarta, Ahli Teknologi Informasi di Yogyakarta. Teknik penentuan informan sangat penting dikarenakan informan lah yang nantinya akan menjadi sumber informasi penelitian. Dalam penelitian ini informan dipilih dengan purposive sampling yaitu memilih informan dengan berdasarkan kriteria (Sugiyono, 2017).

Informan yang dipilih yaitu pengusaha online (e-commerce) yang sedang/masih menjalankan usahanya hingga saat ini yang berdomisili di Yogyakarta, Kantor Pelayanan Pajak (KPP) Pratama Yogyakarta, Konsultan Pajak di Yogyakarta, Pakar Pajak di Yogyakarta, Ahli Teknologi Informasi di Yogyakarta. Pada penelitian ini, teknik pengambilan data dilakukan dengan wawancara kepada informan. Teknik wawancara adalah wawancara tidak berstruktur kepada seluruh informan yang dipilih dengan pedoman yang telah dibuat sebelumnya. Hal pertama yang harus dilakukan dalam analisis data adalah reduksi data. Selanjutnya yaitu penyajian data guna mempermudah peneliti dalam melihat gambaran secara keseluruhan atau bagian tertentu dari penelitian. Langkah yang terakhir yaitu penarikan kesimpulan dengan melakukan verifikasi secara terus menerus sepanjang proses penelitian berlangsung, yaitu selama proses pengumpulan data.

\section{HASIL DAN PEMBAHASAN}

Data hasil penelitian didapatkan melalui kegiatan wawancara yag dilakukan secara mendalam oleh peneliti pada kurun waktu bulan Agustus sampai September 2019. Seluruh informan yang melakukan wawancara mendalam adalah yang berdomisili di Yogyakarta, seperti: Kantor KPP Pratama Yogyakarta, 
Pengusaha Online, Konsultan dan Pakar Pajak dan Ahli Teknologi Informasi di Yogyakarta.

Berdasarkan pada wawancara mendalam yang dilakukan oleh peneliti kepada para informan, seluruh informan menjawab bahwa sudah seharusnya penghasilan yang diperoleh atas transaksi perdagangan online (e-commerce) dikenakan pajak, karena pada dasarnya mereka memperoleh tambahan kemampuan ekonomis atas transaksi perdagangan online (e-commerce) tersebut. Pernyataan tersebut juga telah dikonfirmasi oleh Direktorat Jenderal Pajak bahwa penghasilan perdagangan online (e-commerce) pasti merupakan objek pajak penghasilan. Berkaitan dengan hal tersebut pajak untuk e-commerce belum diterapkan namun sebenarnya perlakuan pajaknya sama dengan yang konvensional yang membedakan sebenarnya tidak ada karena objeknya sama.

Pajak yang dapat dikenakan untuk pengusaha online adalah Pajak Penghasilan (PPh) dan Pajak Pertambahan Nilai (PPN). Pengusaha bisnis online yang dikukuhkan sebagai Pengusaha Kena Pajak adalah pengusaha yang memiliki penghasilan lebih dari 4,8 milyar. Pengusaha online yang telah dikukuhkan sebagai Pengusaha Kena Pajak memiliki kewajiban untuk membayar pajak sehingga harus memungut Pajak Pertambahan Nilai dari Konsumen. Produk yang dijual oleh pengusaha inilah yang dikenakan pajak.

Pemungutan pajak atas penghasilan perdagangan online (e-commerce) bukan merupakan peraturan yang baru. Berdasarkan pada Ketentuan Umum dan Tata Cara Perpajakan, untuk pemungutan Pajak Penghasilan didasarkan pada Undang-Undang Pajak Penghasilan (PPh) dan untuk pemungutan Pajak Pertambahan Nilai didasarkan pada Undang-Undang Pajak Pertambahan Nilai (PPN). Seluruh aspek perpajakan sudah tercantum dalam undang-undang tersebut. Pajak yang dipungut atas transaksi perdagangan online (e-commerce) juga bukan merupakan objek baru melainkan hanyalah proses bisnisnya yang baru. Berkaitan dengan hal tersebut, pemungutan pajak untuk pengusaha online masih didasarkan peraturan yang sudah ada, tidak ada perbedaan dalam pemungutan Pajak Penghasilan untuk pengusaha online dengan pemungutan Pajak Penghasilan untuk pengusaha konvensional.

Berdasarkan hasil wawancara yang telah dilakukan oleh peneliti dengan beberapa informan, dapat diketahui bahwa cara pemungutan pajak untuk pengusaha online sama dengan pemungutan pajak untuk pengusaha konvensional tidak ada pembeda antara keduanya. Pada tahun 2018 Direktorat Jenderal Pajak pernah mengeluarkan peraturan tentang pajak e-commerce namun ditunda penerapannya dikarenakan masyarakat beranggapan bahwa peraturan tersebut merupakan penetapan pajak baru, sementara hal tersebut sebenarnya merupakan penegasan peraturan yang sudah ada. Dengan peraturan yang ditunda tersebut Direktorat Jenderal Pajak juga bertujuan untuk bekerjasama dengan pihak marketplace dalam rangkat sosialisasi pajaknya, Direktorat Jenderal Pajak juga meminta pihak marketplace menyampaikan kepada online shop yang berjualan di marketplace tersebut bahwa tidak ada perbedaan antara pengusaha online dan pengusaha konvensional, serta meminta pihak marketplace membuat laporan bulanan terkait transaksi-transaksi online shop yang berada di marketplace tersebut. Berita itu juga membantu Direktorat Jenderal Pajak dalam rangka 
konsep keadilan pajak itu berjalan, tidak hanya pengusaha konvensional saja yang dikenakan pajak namum pengusaha online juga dikenakan pajak.

Tidak ada pengawasan khusus terkait pengusaha online, seluruh Wajib Pajak diperlakukan dengan sama, Direktorat Jenderal Pajak juga telah memiliki pegawai pengawasan yang mempunyai tugas untuk mengawasi Wajib Pajak. Teknologi Informasi yang dimiliki oleh Direktorat Jenderal Pajak hanya dapat mengawasi secara tidak langsung penghasilan yang diperoleh pengusaha online melalui data uang masuk dan uang keluar, contohnya data pembelian atau biaya hidup. Data tersebut diperoleh ketika pengusaha online melakukan transaksi pembelian yang dipotong pajak dan secara langsung data tersebut akan masuk ke sistem yang dimiliki oleh Direktorat Jenderal Pajak, data yang masuk ke Direktorat Jenderal Pajak yaitu pembelian suatu produk dan selama penjual produk tersebut menerbitkan faktur pajak maka data tersebut akan masuk ke Direktorat Jenderal Pajak.

Untuk memaksimalkan pemungutan pajak pada pengusaha online DJP bisa melakukan kerjasama dengan bank untuk mendeteksi transaksi yang terjadi antara penjual dan pembeli. DJP juga bisa melakukan kerjasama dengan marketplace untuk melacak transaksi yang dilakukan. Perekrutan seorang ahli media sosial yang menangani pengusaha online juga dapat membantu menggali potensi pajak perdagangan online (e-commerce).

Hasil dari wawancara mendalam memperoleh informasi bahwa sebagaian besar pengusaha online takut jika mendengar kata pajak dikarenakan mereka harus membayar pajak dan takut penghasilan yang mereka dapat dipotong sehingga penghasilan yang mereka dapat menjadi berkurang tetapi sebagian besar pengusaha online yang telah diwawancara peneliti mereka sadar bahwa atas penghasilan yang diperoleh atas usaha online merupakan penghasiln yang dikenai pajak. Mereka tidak masalah apabila mereka harus di kenakan pajak. Masih banyaknya pelaku e-commerce di Yogyakarta belum mendapatkan sosialisasi tentang pajak mengakibatkan mereka belum tahu secara jelas terkait dengan kewajiban perpajakan dan kontribusi terhadap negara. Sebagian besar pengusaha online mengetahui informasi tentang pajak hanya melalui internet dan sosial media. Kurangnya informasi tentang pajak membuat sebagian dari mereka tidak memiliki NPWP bahkan mereka tidak tahu cara membuatnya.

Pengusaha online di Yogyakarta yang peneliti wawancara mengatakan bahwa seharusnya perdagangan online (e-commerce) sudah seharusnya dikenakan pajak. Penghasilan yang mereka dapatkan sama dengan penghasilan yang didapatkan pegawai kantor sehingga mereka juga berpotensi dikenakan pajak penghasilan. Apabila kita melihat kembali makna dari pajak penghasilan adalah kemampuan ekonomis yang diperoleh Wajib Pajak, baik yang diperoleh dari Indonesia maupun diperoleh dari luar Indonesia. Sehingga siapapun yang memiliki penghasilan maka merupakan objek pajak dan harus membayar pajak. Pengusaha online juga beranggapan semakin berkembang zaman kedepannya pengusaha yang masih konvensional akan berpindah menjadi berbasis online dikarenakan pemasaran melalui internet lebih mudah daripada berbisnis konvensional. Sehingga sudah seharusnya di kenakan pajak.

Semua pengusaha online yang peneliti wawancara setuju namun sedikit kecewa jika akan diterapkan pajak penghasilan untuk perdagangan online (e- 
commerce) karena penghasilan yang didapat berkurang. Pengusaha online juga menyetujui jika akan diterapkan pajak penghasilan karena supaya adil namun jika akan diterapkan harus ada batasan transaksi yang dikenakan pajak tidak semua online shop melainkan yang sudah memperoleh penghasilan besar saja yang mungkin di pungut pajak. Pengusaha online juga berpendapat bahwa pemungutan pajak (e-commerce) dapat dipungut berdasarkan laba yang mereka peroleh karena laba merupakan penghasilan yang diperoleh setelah dikurangi biaya-biaya. Namun, bagi pengusaha online yang baru menjalankan usaha, laba yang diperoleh umumnya belum cukup untuk menutup biaya investasi, sehingga perlu untuk diberikan batasan yang dikenakan pajak.

\section{SIMPULAN}

Berdasarkan hasil penelitian kualitatif dengan teknik wawancara yang telah dilakukan oleh peneliti dengan beberapa Pengusaha Online (e-commerce), Pakar Pajak, Konsultan Pajak, Ahli Teknologi Informasi dan KPP pratama Yogyakarta maka dapat diambil beberapa kesimpulan, yaitu.

Sudah seharusnya pengusaha online (e-commerce) dikenakan pajak dan penghasilan pengusaha online merupakan objek pajak. Pemungutan pajak atas penghasilan pengusaha online bukan merupakan bentuk aturan baru melainkan penegasan peraturan yang sudah ada, namun pemungutannya belum maksimal dikarenakan sulitnya akses untuk mengetahui besarnya penghasilan pengusaha online secara keseluruhan.

Pemungutan pajak penghasilan bagi pengusaha online saat ini masih seperti pemungutan pajak penghasilan bagi pengusaha konvensional, belum dibentuk peraturan baru yang dikhususkan kepada pengusaha online. Pengenaan Pajak Penghasilan pengusaha online saat ini Direktorat Jenderal Pajak hanya dapat melihat dari biaya hidup pengusaha online seperti transaksi pembelian yang dilakukan pengusaha online tersebut dan didasarkan pada kesadaran Wajib Pajak untuk mematuhi NPWP, membuat dan melaporkan dalam bentuk SPT. Perekrutan tenaga ahli dalam media sosial dan pembentukan divisi khusus untuk mengawasi $e$-commerce juga diperlukan untuk memaksimalkan pemungutan pajak terhadap e-commerce.

Pengusaha bisnis online setuju apabila dikenakan pajak namun harus ada batasan transaksi yang dapat dikenakan pajak penghasilan. Pengusaha online juga berpendapat bahwa pemungutan pajak (e-commerce) dapat dipungut berdasarkan laba yang mereka peroleh karena laba merupakan penghasilan yang diperoleh setelah dikurangi biaya-biaya

Atas penelitian yang telah dilakukan, terdapat beberapa saran bagi penelitian selanjutnya, yaitu, Kurangnya sosialisasi mengenai perpajakan menyebabkan kurangnya kesadaran pengusaha online terhadap kewajiban perpajakan. Oleh karena itu Direktorat Jenderal Pajak disarankan untuk mengadakan sosialisasi agar para pengusaha online lebih mengetahui bahwa penghasilannya sudah harus dikenakan pajak. Pemerintah diharapkan segera membentuk peraturan prundang-undangan terkait dengan pajak e-commerce agar potensi pajak yang ada segera dapat terserap. Untuk penelitian selanjutnya disarankan untuk memperluas wilayah penelitian tidak hanya di Daerah Istimewa Yogyakarta agar hasil yang diperoleh lebih berkembang. 


\section{REFERENSI}

Adam, D. V., \& Astin, I. P. (2019). Kebijakan Pengenaan Pajak atas Transaksi Online (E-Commerce). Festival Riset Ilmiah Manajemen Dan Akuntansi (FIRMA).

Adityowati, Putri, \& Vindry Florention. (2016). “Apa Kata Bos Bukalapak tentang Pajak E-Commerce?" Retrieved from Tempo website: https://m.tempo.co

Arimbhi, P., Susanto, I., \& Ghany, S. K. (2019). Proses Bisnis dan Aspek Pemungutan Pajak atas Transaksi E-commerce dalam Era Revolusi Industri 4.0. Jurnal Reformasi Administrasi, 6(1), 53-67.

Australia Government. (2019). Strategic direction | Australian Taxation Office. Retrieved July 18, 2019, from Australia Taxation Office website: https://www.ato.gov.au/ About-ATO/Managing-the-tax-and-supersystem/Strategic-direction/

Australian Government. (2019). About ATO | Australian Taxation Office. Retrieved July 18, 2019, from Australia Taxation Office website: https://www.ato.gov.au/About-ATO/

Avalara Vat live. (2019). Australia GST on e-commerce 1 July 2018 - Avalara. Retrieved July 18, 2019, from Avalara.com website: https://www.avalara.com/vatlive/en/vat-news/australia-gst-on-ecommerce-1-july-2018.html

Awa, H. O., Awara, N. F., \& Lebari, E. D. (2015). Critical factors inhibiting electronic commerce (EC) adoption in nigeria: A study of operators of SMEs. Journal of Science and Technology Policy Management, 6(2), 143-164. https://doi.org/10.1108/JSTPM-07-2014-0033

Azanella, L. A. (2019). Pajak "E-Commerce" Diberlakukan 1 April 2019, Begini Aturannya. Retrieved April 26, 2019, from Kompas website: https://ekonomi.kompas.com/read/2019/01/15/145537326/ pajak-ecommerce-diberlakukan-1-april-2019-begini-aturannya

Buchori, M. Al. (2019). Media Sosial, Tantangan Media Massa di Era Digital oleh Mahfud Al Buchori Halaman all - Kompasiana.com. Retrieved May 8, 2019, from Kompasiana website: https://www.kompasiana.com/mahfudalbuchori/5c525fd8c112fe4ba6454cc4/media-sosial-tantangan-media-massadi-era-digital?page=all\#

Cahyono, A. S. (2016). Pengaruh Media Sosial Terhadap Perubahan Sosial Masyarakat di Indonesia. Jurnal Ilmu Sosial Dan Ilmu Politik Diterbitkan Oleh Fakultas Ilmu Sosial Dan Politik, Universitas Tulungagung, 9(1), 140-157.

Daud, A., Sabijono, H., \& Pangerapan, S. (2018). Analisis Penerapan Pajak Pertambahan Nilai Pada PT. Nenggapratama Internusantara. d(2), 512-528.

Direktorat Jendal Pajak. (2013). Perubahan Undang-undang Nomor 6 tahun 1983 tentang Ketentuan Umum dan tata Cara Perpajakan. Direktorat Jendral Pajak.

Dolfen, P., Einav, L., Klenow, P. J., Klopack, B., Levin, J. D., Levin, L., \& Best, W. (2019). Assessing The Gains from E-Commerce. Retrieved from http://www.nber.org/papers/w25610

Donaldson, L., \& Davis, J. . (1991). Stewardship Theory or Agrnvy Theory: CEO Governance and Shareholder Returns. Australian Journal of Management, 16(1), 49-64. https:/ / doi.org/https:/ / doi.org/10.1177/031289629101600103 
Fox, W. F. (2001). State and Local Sales Tax Revenue Losses from E-Commerce: Updated Estimates. 4170(September).

Garín-Muñoz, T., López, R., Pérez-Amaral, T., Herguera, I., \& Valarezo, A. (2019). Models for Individual Adoption of eCommerce, eBanking and eGovernment in Spain. Telecommunications Policy, 43(1), 100-111. https://doi.org/10.1016/j.telpol.2018.01.002

Hellerstein, \& Walter. (2002). Electronic Commerce and The Challenge for Tax Administration. Paper in Seminar on Revenue Implications of E-Commerce for Development, Geneva, Switzeland.

Hermanto, W. (2016). Analisis Pengaruh Kepercayaan, Kemudahan dan Kualitas Informasi Terhadap Keputusan Pembelian Secara Online.

Kahraman, N., Tunga, M. A., Ayvaz, S., \& Salman, Y. B. (2010). Understanding the Purchase Behaviour of Turkish Consumers in B2C E-Commerce. International Journal of Intelligent Systems and Applications in Engineering, 7(2), 2058-2061. https://doi.org/10.1039/b000000x

Khasanah, U., T, S., \& Mardiati, E. (2019). Coercive Authority and Trust in Tax Authority in Influencing Voluntary Tax Compliance: A Study of Slippery Slope. Journal of Accounting and Investment, 20(1). https://doi.org/10.18196/jai.2001109

Kinder, T. (2002). Emerging e-commerce business models: An analysis of case studies from West Lothian, Scotland. European Journal of Innovation Management, 5(3), 130-151. https://doi.org/10.1108/14601060210436718

Kumparan. (2018). Ragam Regulasi Pajak E-commerce di Dunia - kumparan.com. Retrieved July 16, 2019, from Kumparan website: https://kumparan.com/@kumparanbisnis/ragam-regulasi-pajak-ecommerce-di-dunia

Laohapensang, O. (2009). Factor Influencing Internet Shopping Behavior: a survey of consumers in Thailand. Jurnal of Fashion Marketing and Management, 13(4), 501-513.

Lim, S. A., \& Indrawati, L. (2014). Perlakuan Pajak Pertambahan Nilai Transaksi ECommerce Di Indonesia. 36-57.

Linzbach, P., Inman, J. J., \& Nikolova, H. (2019). E-Commerce in a Physical Store: Which Retailing Technologies Add Real Value. NIM Marketing Intelligence Review, 11(1), 42-47. https:/ / doi.org/10.2478/nimmir-2019-0007

Makalalag, L. (2016). Pengenaan Pajak Penghasilan Terhadap Pengusaha Dalam Transaksi Perdagangan Online (E-Commerce). Jurnal Ilmu Hukum Legal Opinion, 4(1), 1-10. https:/ / doi.org/10.1360/zd-2013-43-6-1064

Nugroho, B. ade febrianto. (2016). Mekanisme Pemungutan Pajak Pertambahan Nilai untuk E-Commerce di Indonesia Menggunakan E-Wallet.

Pangesti, R. D. (2017). Menguak Permasalahan Perpajakan E-. Jurnal Riset Akuntansi Dan Bisnis Airlangga, 2(1), 181-201.

Pilkington, C., \& Farron, S. (2013). International Direct Taxation of E-commerce: Developing a New Conceptual Model From Marketing Principles. Journal of Chemical Information and Modeling, 53(9), 1689-1699. https:// doi.org/10.1017/CBO9781107415324.004

Rahayu, N. (2019). Pertumbuhan E-Commerce Pesat di Indonesia. Retrieved April 21, 2019, from Porta Berita Ekonomi website: 
https://www.wartaekonomi.co.id/read216302/ pertumbuhan-e-commercepesat-di-indonesia.html

Rahman, I. A., \& Panuju, R. (2017). Trategi Komunikasi Pemasaran Produk Fair N Pink Melalui Media Sosial Instagram. Jurnal Ilmiah Ilmu Komunikasi, 16(2), 214-224.

Rainer, R. K., \& Cegielski, C. G. (2013). Introduction to Information Systems. 4th editio.

Rohm, A. J., Kashyap, V., Brashear, T. G., \& Milne, G. R. (2004). The use of online marketplaces for competitive advantage: A Latin American perspective. Journal of Business and Industrial Marketing, 19(6), 372-385. https://doi.org/10.1108/08858620410556318

Ruiz, M. (2018). Chinese Customs Regulations on Cross-Border E-Commerce: A Growth Opportunity for Foreign Enterprises and Chinese Commercial $\begin{array}{llll}\text { Platforms. Sinología } & \text { Hispánica, }\end{array}$ https://doi.org/10.18002/ sin.v1i6.5492

Saleh, E. (2004). Teknologi Pengolahan Susu dan Hasil Ikutan Ternak. USU Digital Library, (1987), 1-7.

Sari, R. P. (2018). Kebijakan Perpajakan atas Transaksi E-Commerce. Journal Feb Unmul AKUNTABEL, 1.

Smeait, A. (2016). Faktor-Faktor Yang Mempengaruhi Minat Beli Pada Produk Fashion Melalui Belanja Online.

Sofyani, H., Tahar, A., \& Murtin, A. (2019). Perpajakan Di Indonesia (1st ed.; S. rezki Hayati, Ed.). BASKARA MEDIA.

Su, W., Wang, Y., Qian, L., Zeng, S., Baležentis, T., \& Streimikiene, D. (2019). Creating a Sustainable Policy Framework for Cross-Border E-Commerce in China. Sustainability (Switzerland), https://doi.org/10.3390/su11040943

Tahar, A., \& Rachman, A. K. (2016). Pengaruh Faktor Internal dan Faktor Eksternal Terhadap Kepatuhan Wajib Pajak. Jurnal Akuntansi Dan Investasi, 15(1), 56-67.

Tshandra, N. (2018). 80 Persen Konsumen Belanja Online Orang Muda dan Wanita. Retrieved May 8, 2019, from Kompas website: https://lifestyle.kompas.com/read/2018/03/22/155001820/80-persenkonsumen-belanja-online-orang-muda-dan-wanita

Ulya, F. N. (2019). Pasar E-Commerce Indonesia Diprediksi Tumbuh hingga 20 Miliar Dollar AS. Retrieved April 23, 2019, from Kompas website: https://money.kompas.com/read/2019/03/26/181200726/pasar-ecommerce-indonesia-diprediksi-tumbuh-hingga-20-miliar-dollar-as

Viana, E. R., Margareth, P., \& Serly. (2017). Menelisik Pajak Penghasilan Atas Bisnis Online Shop. Jurnal Infestasi, 13(2), 367-379.

Viboonthanakul, S. (2009). Smuggling via e-commerce: Effect on tax revenue. Journal of International Trade Law and Policy, 8(3), 272-290. https:// doi.org/10.1108/14770020910990650

Wahyudi, E. (2015). Memahami Organisasi Pengelolaan Pajak di The Australian Taxation Office (ATO) Canberra. Retrieved July 18, 2019, from https://eddiwahyudi.com/2015/01/11/memahami-organisasipengelolaan-pajak-di-the-australian-taxation-office-ato-canberra/

Wan, F., \& Chen, Q. (2018). The Factors Affecting the Development of Cross-border E-commerce in China. DEStech Transactions on Economics, Business and 
Management, (eced), 58-61. https://doi.org/10.12783/dtem/eced2018/23934 Xiao, Z. (2017). the Development of E-Commerce in Europe. Thessis. Centria University of Spplied Sciences, Business Management.

Yapar, B. K., Bayrakdar, S., \& Yapar, M. (2015). The Role of Taxation Promblems on the Development of E-Commerce. Social and Behavioral Sciences, 195, 642648. 